\title{
Applied Algebra with Laboratory Experimentation
}

\author{
Richard Ciocci, Cathy Godbois, Eric Leung \\ Harrisburg Area Community College
}

This paper describes a work in progress. Students in a variety of majors at the community college-level are required to take at least two courses in math and science. Often these students elect to take college algebra, which neither prepares them for a data-oriented environment in the workplace nor exposes them to scientific methodology. These students need an interdisciplinary course or a course with an interdisciplinary focus, which gives them these necessary skills. The National Science Foundation (NSF) awarded an Instrumentation and Laboratory Improvement Leadership in Laboratory Development Grant, 96-51137, to three faculty members at Harrisburg Area Community College to develop a text, lab manual, and course to meet this need. This paper discusses the methodology behind the text, manual, and course and gives examples of the lab experiments to be used.

\section{Introduction}

Harrisburg Area Community College (HACC) recognizes that scientific and technological literacy is crucial to meet the needs of our graduates as they enter the workforce. However, many undergraduates at HACC and at other colleges or universities can complete degree requirements without ever taking courses that will help them acquire this literacy. One reason this occurs is that in associate-degree career and transfer programs that are not technological in nature, students are required to take at most two courses in mathematics and the sciences. Approximately onehalf of all students in a degree program at HACC are part of this population. These students often graduate without developing scientific and technological literacy.

The National Science Foundation NSF awarded an Instrumentation and Laboratory Improvement Grant to three faculty members from the Mathematics, Engineering, and Technology Division at HACC. The grant, awarded under the NSF's Leadership in Laboratory Development program, was made for the investigators to develop a text and a laboratory manual for an interdisciplinary and applied alternative to college-level algebra. The curricular materials described herein are written so that the students can investigate basic science laws and develop models for observed real-world phenomena using scientific methodology and data analysis on the data they have collected. The materials developed include experiments and simulations from a variety of disciplines, which the students will conduct. Students, working collaboratively, will use scientific methodology to gather data, develop data analysis and modeling methods to introduce functions, and present the functions, numerically, graphically, symbolically, and verbally.

\section{Project Status}

The text and lab manual exist in class test form and significant portions of each have been class tested. A local high school has class-tested the text in its college algebra course. A series of the experiments was tested by a team of high school students at a summer institute at HACC. The 
faculty team worked with a publisher as they developed the materials, and potential beta test sites have been identified to class-test the materials. Development of the materials has been done with the help of faculty in the mathematics, engineering, and physics departments of the college. The grant also includes funds for reviews by faculty in client disciplines, e.g., business and social science. The faculty team working on this project has delivered seven presentations and workshops at national conferences seeking reaction and comments on the materials and the innovative approach. Three more presentations are planned during the first half of 1998.

Methodology

The primary focus of the work is to foster collaborative learning through experimentation. The lab instructions are written for the students to explore the physical phenomena to determine what must be measured, what relationship exists between variables, and what function best describes the relationship. Beyond the written materials, the faculty team is developing a course in applied algebra using the same focus, and the college will offer that course as a special topic.

\section{Text}

The text is divided in eight chapters with the titles of: "Connections," "Linear Functions," "Exponential and Logarithmic Functions," "Power Functions," "Quadratic Functions," "Combining Functions," "Polynomial and Rational Functions," and "Linear Systems and Matrices." Although the topics include those found in a traditional college algebra course, the sequencing and approach are profoundly different. For example, a discussion of an experiment on Hooke's Law is used to introduce the concept of function in the first chapter. The experiment also motivates a discussion of categorical versus quantitative, univariate versus bivariate, experimental versus observational data, experimental design and control, confounders, and measurement error. The first chapter also includes a discussion of data analysis, linear regression, and model verification techniques.

Analysis of experimental results is a recurring theme included in all of the function chapters. Experimental results are used to motivate the discussion of important mathematical concepts throughout the text. For example, a discussion of the force of a compressed or extended spring on a frictionless horizontal surface is used to introduce the concept of an odd function. Analysis of experimental results also includes discussion of modeling techniques to help students recognize functional relationships between measured quantities.

\section{Lab Manual}

The manual contains twenty-seven experiments divided into ten topical areas. The topics are: "Simple Experiments and Simulations," "Hooke's Law," "Resistance," "Basic Electrical Laws," "Optics," "Properties of Gases," "Properties of Fluids," "Heat and Thermodynamics,"

"Mechanics," and "Vibrations." Labs are written for the students and an accompanying guide for each lab is written for the instructor. Each lab includes an objective, some scientific theory, equipment and materials requirements, and suggested procedures and analyses. The labs include a series of questions designed to guide students toward developing a testing method, collecting 
the data, and analyzing it.

As an example, one lab is written to have students determine a model for the resistance in a wire. Using the discussion of the physical and chemical properties of a spring and the affect of each on the displacement of the spring in the text, students are expected to identify the physical and chemical properties of a wire that could affect the resistance through it. After identifying several properties, students are expected to design a series of experiments to determine how these properties, e.g., diameter and length, affect resistance. Upon completion of each experiment in the series, students are asked to develop a scatter plot of the data, test the data to determine an appropriate model, verify the model with a residual plot, and use a graphing calculator to construct the best-fit model for the data. Students should be able to identify the linear relationship between length and resistance and the inverse square relationship between diameter and resistance.

The equipment used in the experiments varies. The experiments on the resistance of a wire, described above, are done with a wheatstone bridge. Students use a digital multimeter for the experiments on basic electrical laws. Some experiments require the Texas Instruments' CBL data collection equipment. For example, the measurement of the decay of light from a source once the light is turned off requires the use of computerized equipment as the time measurement is too short for the eye and brain to detect accurately. A graphing calculator, the TI83, is used to create a scatter plot of the data, perform additional numerical tests to identify a model, construct the least squares regression model, and construct a residual plot to verify the chosen model is appropriate. As with all experimentation, students are asked to consider potential measurement errors that could occur in their procedure. Multiple measurements of the same variable and data averaging are means suggested for overcoming this type of error.

\section{Course}

The course, temporarily designated Math 282 Applied College Algebra, is a college-level course with an interdisciplinary focus. The prerequisite for the course is an intermediate algebra course with a grade of "C" or better. Math 282 is designed to be an alternative to the traditional college algebra course, Math 103. Besides its focus on collaborative experimentation, the new course provides a sound foundation for continued coursework in mathematics including trigonometry, statistics, and applied calculus.

The Mathematics Section of the college approved Math 282 with a two-hour-per-week lecture component and a three-hour-per-week laboratory component. In retrospect, however, it seems that the course will require a three-hour-per-week lecture component. A two-hour-per-week laboratory component should be sufficient to complete the labs designated for the course.

\section{Relationship to Traditional College Algebra}

An interesting sidebar is the reaction of the collective mathematics faculty at HACC to the applied algebra course. Both the reformists and the traditionalists in the section accept Math 282 and support its use in a number of programs at the college. Traditionally, college algebra has 
been taught for the students who continue in the math sequence to calculus. Approximately half the students at HACC who take Math 103, College Algebra, do so as either a math/science elective or as the highest-level math course they need for graduation. The students who do not need the traditional background to be ready for calculus do need the applied approach to experience the scientific method.

Both groups in the Mathematics faculty like Math 282. The reformists like the applied algebra course because it stresses collaborative learning, includes experimentation, and uses actual examples. A number of mathematics faculty members have tried experiments within their traditional lecture-only classes. Math 282 allows for additional time to be spent on the experiments so the students can work with classmates on the experiments and on the data analysis. Traditionalists like Math 282 because it allows them to teach those who take Math 103, College Algebra, with the objective of having their students learn the algebra as a foundation for calculus. The effect of having an alternative for algebra is that the students needing just algebra get a scientific experience with the experimentation, and the students needing algebra as a preparation for calculus get a more-focused course that is a better foundation for them.

\section{The Plan from Here}

The faculty team has yet to run the course for the first time. A section was offered in the Fall 1997 and the Spring 1998 semesters. Enrollment was not sufficient to run the course. One problem identified with the low enrollment was the transferability of the course due to the designation of a topics course number, 282. The faculty team will proceed with obtaining a formal course number and work with the counseling staff on the transferability issue. The faculty team will also encourage colleagues in the academic divisions that are responsible for programs in the health fields, the business areas, and the social sciences to reevaluate the programs for potential inclusion of applied algebra. There are various degree programs at the college where Math 103 is the highest-level math course required, and many others accept Math 103 as a math/science elective. Conclusion of the mission to promote applied algebra comes when the new course is adopted by as many programs as is reasonable for the students involved.

RICHARD CIOCCI, PE, is an instructor in the engineering and mechanical engineering technology programs at the Wildwood campus of Harrisburg Area Community College. Rick earned his masters degree in engineering management at the University of Dayton and is currently a part-time PhD student at the University of Maryland. He regularly teaches courses in statics, dynamics, computer numerical control, and computer-aided drafting.

CATHY GODBOIS is an instructor of mathematics at the Lancaster campus of Harrisburg Area Community College. Cathy earned her masters degree in mathematics from and is currently a part-time PhD student at the University of Texas at Arlington. She regularly teaches courses in algebra, calculus, computer programming, and electronics. Cathy is the principal investigator for the NSF ILI-LLD grant.

ERIC LEUNG, $\mathrm{PhD}$, is an instructor of mathematics having taught at both the Lebanon and Wildwood campuses of Harrisburg Area Community College. Eric earned his doctorate in mathematics at the University of Iowa. He regularly teaches courses in the various levels of algebra, pre-calculus, and computer programming (QBASIC, FORTRAN, and JAVA). 